\title{
Exotic Plants of Theodore Roosevelt National Park
}

\author{
JACK L. BUTLER • DEPARTMENT OF BIOLOGY \\ UNIVERSITY OF SOUTH DAKOTA $\downarrow$ VERMILLION
}

\section{$\checkmark \quad$ RESEARCH SUMMARY}

The 1992 field season began in early May with a meeting between the principal investigator and NPS Unit Technical Representatives. The primary objectives of the second field season was to 1) continue with the initial survey so that the number and distribution of exotic plant species within the Park could be estimated, 2) take low-level aerial photographs (slides) of the South Unit so that general areas of leafy spurge infestations could be mapped, 3 ) continue to evaluate the existing ecological effects of exotics on the native constituents, and 4) estimate density and composition of exotics within the soil seed bank.

A systematic search of both the North and South Units was continued during the 1992 field season. An attempt was made to select a combination of specific study sites which represented the entire physiographic unit as a whole from heavily infested to non-infested. Two, parallel $25 \mathrm{~m}$ line transects were place at each selected site. Quadrats $(20$ X 50 $\mathrm{cm})$ were placed in a cover class as described by Daubenmire (1959). A two-meter belt transect recorded the occurrence of any exotic plant species not observed in the quadrats. Specimens were collected of all exotic plant species found within the Park and are currently being processed and mounted according to standard herbarium procedures.

Aerial photographs (slides) were taken in the South Unit during peak flowering of leafy spurge in early June. The slides were taken from a fixed- winged aircraft fitted with a belly-mounted $35 \mathrm{~mm}$ camera and flown from a height of about $1500 \mathrm{~m}$ above ground level. The slides are currently being examined to see if general areas of leafy spurge infestations can be mapped. Preliminary results indicate that the level of resolution is generally inadequate for accurately mapping sites infested with leafy spurge.

Aboveground biomass, by species, was harvested during peak standing crop (August) for 1992 on sites lightly, moderately and heavily infested with leafy spurge, smooth brome, downy brome and Japanese brome. Further, the current year's growth of several selected woody plant species which are common to the Green Ash Draw Habitat Type was harvested from sites heavily infested with leafy spurge and from non-infested sites. Pellet transects, as described by Marlow et al. (1984), were established within several selected habitat types infested with leafy spurge. The frequency of pellet groups within infested sites will be compared to noninfested sites so that the effects of leafy spurge infestation on habitat utilization by native ungulates can be evaluated.

Soil samples were collected from 1) noninfested, infested and peripherally infested leafy spurge sites, 2) non-infested and infested smooth brome sites, and 3) several randomly located sites not infested with leafy spurge, smooth brome, downy brome or Japanese brome. The samples were sifted, thoroughly mixed and divided into two equal portions. One portion was moistened and then stored 
176

in a plastic bag for about 10 weeks at $1-3^{\circ} \mathrm{C}$ for stratification. The remaining sample was uniformly spread to a depth of $3 \mathrm{~cm}$ on top of $3 \mathrm{~cm}$ of a sterile vermiculite-peat moss mixture in a standard seeding flat. The flats were randomized on a greenhouse bench. Germination trials are currently being conducted. Preliminary results indicate that the number of seedlings emerging from sites infested with leafy spurge is significantly greater compared to non-infested sites (Table 1). The two species emerging from the flats have been tentatively identified as leafy spurge and downy brome.

Table 1. Mean number of emerged seedlings recorded from 20 X $40 \mathrm{~cm}$ soil samples collected within noninfested, infested and peripherally infested leafy spurge sites in Theodore Roosevelt National Park (sample sizes are within parenthesis) during the first two weeks of germination trials.

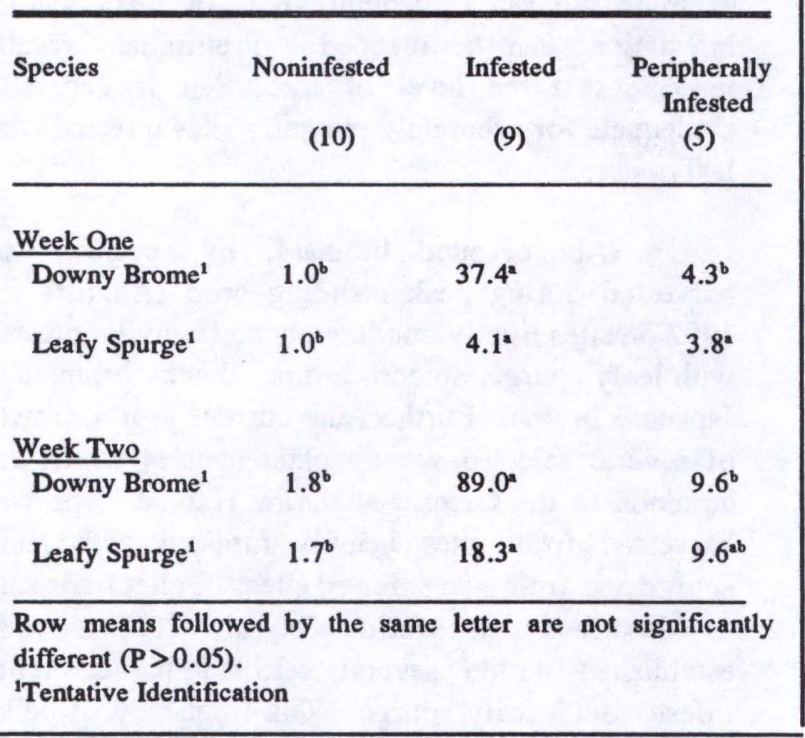

\section{PROBLEMS}

Mapping the general areas of leafy spurge infestation from the aerial photographs (slides) with any confidence will be a problem. The photographs were taken from a relatively low flying aircraft; however, the level of resolution is inadequate for any kind of accurate mapping. The maps will require substantial ground verification if they are to have any utility. This is a common problem which has been voiced from other scientists who also have tried to aerially map leafy spurge infestations. I will continue to work on the maps but I am not optimistic.

\section{$\checkmark \quad$ LITERATURE CITED}

Marlow, C.B., L.R. Irbry and J.E. Norland. 1984. Optimum carrying capacity for bison in Theodore Roosevelt National Park. Report submitted to National Park Service. Montana State University, Bozeman. 